\title{
Circulating tumor cells correlate with patterns of recurrence in patients with hormone-sensitive prostate cancer
}

This article was published in the following Dove Press journal:

OncoTargets and Therapy

31 July 2017

Number of times this article has been viewed

\author{
Giandomenico Roviello ${ }^{1,2}$ \\ Silvia Paola Corona ${ }^{3}$ \\ Alberto Bonetta ${ }^{4}$ \\ Maria Rosa Cappelletti ${ }^{5}$ \\ Daniele Generali ${ }^{2,5}$ \\ 'Medical Oncology Unit, Department \\ of Oncology, San Donato Hospital, \\ Arezzo, ${ }^{2}$ Department of Medical, \\ Surgery and Health Sciences, \\ University of Trieste, Trieste, Italy; \\ ${ }^{3}$ Radiation Oncology Department, \\ Peter MacCallum Cancer Centre, \\ Moorabbin Campus, East Bentleigh, \\ VIC, Australia; ${ }^{4}$ Radiotherapy \\ Department, ${ }^{5}$ Breast Cancer Unit, \\ Azienda Socio-Sanitaria Territoriale \\ di Cremona, Cremona, Italy
}

\begin{abstract}
The aim of this study was to evaluate the correlation between circulating tumor cells (CTCs) and patterns of recurrence in patients with hormone-sensitive prostate cancer. The study involved patients with histologically confirmed, advanced prostatic adenocarcinoma, who were tested for CTCs $\left(\right.$ Veridex $^{\circledR}$ ) when they developed recurrence after radical prostatectomy or external beam radiation between 2008 and 2014. Forty-two prostate cancer patients were evaluated. CTCs were detected in 14 out of 42 (33.3\%) patients (Group A), while the remaining $28(66.7 \%)$ showed undetectable levels of CTCs (Group B). The mean prostate-specific antigen value was higher in Group A in comparison to Group B (6.2 vs $3.3 \mathrm{ng} / \mathrm{dL})(P=0.48)$. Presence of bone metastases alone or along with nodal metastases was more common in Group A (57.1\%) in comparison to Group B $(25 \%)(P=0.04)$. In a univariate analysis, the presence of CTCs at diagnosis correlated with the development of bone recurrence (OR: 4; 95\% CI: 1.0-15.9; $P=0.05)$. Even if the study enrolled only a small number of patients, the detection of CTCs in the blood appears to correlate with the pattern of progression in patients with hormone-sensitive prostate cancer, suggesting a possible role in anticipating recurrence at the bone in men with higher tumor load. Further prospective studies are warranted in this setting.
\end{abstract}

Keywords: prostate cancer, CTCs, bone metastasis, biochemical failure

\section{Introduction}

Prostate cancer is the second leading cause of cancer-related deaths in men in most Western countries, and the optimal strategy of treatment in early disease includes radical prostatectomy. ${ }^{1}$ However, external beam radiation therapy is sometimes preferred, as it is associated with a reduction in both early and late complications. ${ }^{2}$ Unfortunately, the $20 \%-40 \%$ of patients undergoing radical prostatectomy ${ }^{1,2}$ and the $30 \%-50 \%$ of patients undergoing radiotherapy (RT) experience recurrence within 10 years. ${ }^{3}$ In this setting, clinical and histopathological factors, such as baseline prostate-specific antigen (PSA) levels, pathologic tumor and lymph node stage, Gleason score, surgery and PSA doubling time have been evaluated for their prognostic and predictive role. ${ }^{4}$ However, the identification of patients with high risk of local and/or distant recurrence still remains difficult, and new predictive biomarkers are needed. High-risk prostate cancer patients undergoing treatment often experience biochemical recurrence, also apart from developing bone metastases, with related clinical complications and a decline in the quality of life. In this setting, it is reported that the use of adjuvant bisphosphonates may help in delaying tumor-related skeletal events. ${ }^{5}$ Close monitoring of patients and the identification of new predictive markers of recurrence could benefit
Correspondence: Giandomenico Roviello Medical Oncology Unit, Department of Oncology, San Donato Hospital, Via Nenni 20, Arezzo 52100, Italy Tel +390577586 I39

Email giandomenicoroviello@hotmail.it 
patients who may need further adjuvant treatment to prevent bone metastases and the associated complications.

Circulating tumor cells (CTCs) are cancer cells detectable in the peripheral blood after probably being released by the tumor. CTCs showed prognostic significance either before or during systemic therapy in prostate cancer. ${ }^{6}$ Moreover, in patients with metastatic disease, the presence of CTCs correlates with decreased overall survival. ${ }^{7,8}$ Finally, it has been shown that CTCs also predict responsiveness to hormonal therapy or chemotherapy in patients with prostate cancer. ${ }^{89}$ However, very few data are available on the correlation between CTC positivity and patterns of recurrence in patients with hormone-sensitive prostate cancer. The aim of this study was to investigate the presence of a correlation between CTC positivity and risk of recurrence in patients with hormone-sensitive prostate cancer.

\section{Patients and methods}

\section{Eligibility criteria}

This study involved patients with histologically confirmed, advanced prostatic adenocarcinoma treated at the Radiotherapy Department, Azienda Socio - Sanitaria Territoriale di Cremona, Italy, who showed recurrence after radical prostatectomy or external beam radiation therapy between 2008 and 2014. Hormone therapy and whole-pelvis radiation were used at the discretion of the treating physician. Patients who received adjuvant RT (initiated $<6$ months after radical prostatectomy) were included. Prior adjuvant hormonal therapy was allowed if the duration of therapy was $\leq 24$ months and progression had occurred $>12$ months after completion of therapy.

\section{Follow-up and definition of outcome}

Follow-up after primary treatment included medical examination and PSA dosage every 3 months for the first 2 years and every 6 months after 2 years. Biochemical failure was defined as an increase of PSA $\geq 0.2 \mathrm{ng} / \mathrm{mL}$ at least twice, as per American Urological Association (AUA) recommendation; ${ }^{10}$ PSA rise $>2 \mathrm{ng} / \mathrm{mL}^{11}$ for patients who underwent RT; and PSA doubling time $<6$ months. ${ }^{12}$ During recurrence, diagnostic imaging was performed, including computed tomography (CT), positron emission tomography (PET)/CT or bone scan, at the discretion of the treating physician. Metastatic disease was defined by the presence of bone and/or soft tissue involvement. A clinical database was established, which contained patient characteristics, tumor grading according to Gleason score and follow-up details, including PSA concentrations.

\section{Ethical approval}

All procedures were performed according to the ethical standards of the institutional research committee and with the Declaration of Helsinki 1964 and later amendments or comparable ethical standards. The study was approved by the Ethics Committee of Azienda Socio - Sanitaria Territoriale di Cremona. Informed written consent was obtained from all participants included in this study.

\section{CTC isolation method}

A peripheral blood sample was collected for the evaluation of CTCs. Isolation and enumeration of CTCs was performed using Veridex CellSearch ${ }^{\circledR}$ assay. For CTCs enumeration, $20 \mathrm{~mL}$ of whole blood was drawn into two proprietary CellSave tubes (Veridex). CTC positivity was defined as $\geq 5 \mathrm{CTCs} / 7.5 \mathrm{~mL}$. After immunomagnetic capture, the CTCs were labeled with a fluorescent nucleic acid dye, 4',6-diamidino-2-phenylindole. The identification and quantification of CTCs was performed by the CellTracks Analyzer II, a semiautomated fluorescence microscope that enables computer-generated reconstruction of cellular images. CTCs are defined as nucleated cells expressing cytokeratins (CKs) 8, 18 and 19 and lacking CD45.

\section{Statistical considerations}

The aim of this study was to evaluate whether CTCs correlate with patterns of recurrence in patients with hormone-sensitive prostate cancer. The CellSearch detection assay, is approved by the US Food and Drug Administration and was used for the counting of CTCs. ${ }^{6}$ For trial purposes, patients were divided into two groups: group A containing patients with positive CTC result ( $\geq 5 \mathrm{CTCs} / 7.5 \mathrm{~mL}$ ) and group B having patients with negative CTC samples ( $<5 \mathrm{CTCs} / 7.5 \mathrm{~mL}$ ).

For statistical analysis purposes, a preliminary data exploration was performed. Numerical variables were expressed as median and range, and these were compared using nonparametric tests (Mann-Whitney $U$-test). Qualitative data were expressed as frequencies and organized into contingency tables; the association between categorical variables was investigated by means of the Fisher's exact test or Person's chi-square. Time-dependent variables were calculated according to the Kaplan-Meier method. Logistic regression analysis was done to identify the applicability of positive CTC results in the prediction of metastatic recurrence. For the entire statistical analysis, the significance level was established at $P<0.05$. All data were analyzed using STATA software. 


\section{Results}

\section{Patient characteristics}

From September 2008 to June 2014, peripheral blood samples of 42 prostate cancer patients with recurrence after primary treatment were analyzed. CTCs were detected in 14 patients out of 42 (33.3\%, Group A), while these were undetectable in the remaining 28 patients (66.7\%, Group B) (Figure 1). The characteristics of the 42 enrolled patients are shown in Table 1 . The median age was 65 years (63 and 66 years in the groups A and B, respectively). There was no statistically significant difference in the type of primary treatment between the two groups. Moreover, 8 patients $(57.1 \%)$ in Group A and 8 (28.5\%) in Group B had a Gleason score $\geq 8$.

\section{Correlation data}

At the median follow-up of 56 months, all patients were alive. The median time to recurrence was 32 months (95\% CI: 14-42 months) in Group A and 40 months ( $95 \%$ CI: $12-72$ months) in Group B ( $P=0.6)$ (Table 2$)$. The mean value for PSA was $4.3 \mathrm{ng} / \mathrm{mL}$, with a nonsignificant, higher value in Group A in comparison to that in Group B ( $6.2 \mathrm{vs} 3.3 \mathrm{ng} / \mathrm{dL} ; P=0.48)$. The main site of recurrence was the bone $(39.5 \%)$.

Table 3 reports the data on the correlation among primary treatment, Gleason score and sites of recurrence per group. No statistically significant difference was observed between groups $\mathrm{A}$ and $\mathrm{B}$ in terms of primary treatment $(P=0.25)$ or Gleason score $(P=0.07)$. Bone metastases alone or associated with nodal metastases were more frequent in Group $\mathrm{A}$ $(57.1 \%)$ in comparison to that in Group B $(25 \%)(P=0.04)$. Moreover, 5 patients $(35.7 \%)$ had local recurrence and 1 patient (7.1\%) had biochemical failure in Group A, but no nodal recurrence was seen. In Group B, 9 patients (32.1\%) had local recurrence; 6 (21.4\%) had biochemical failure

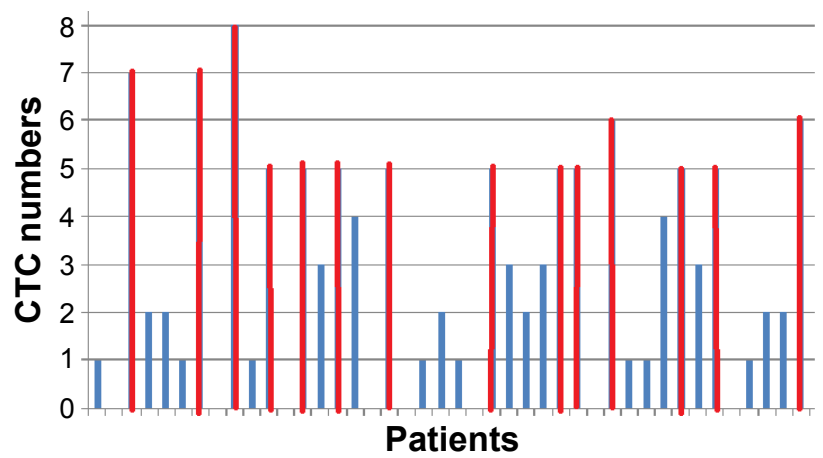

Figure I Occurrence of CTCs.

Note: Red bars indicate the CTC-positive patients; blue bars indicate the CTCnegative patients.

Abbreviation: CTC, circulating tumor cell.
Table I Patient characteristics

\begin{tabular}{|c|c|c|c|}
\hline $\begin{array}{l}\text { Characteristics of } \\
\text { enrolled patients }\end{array}$ & $\frac{\text { Overall }}{\mathbf{N}=42}$ & $\frac{\text { Group A }}{n=14}$ & $\frac{\text { Group B }}{n=28}$ \\
\hline Median age, years & 65 & 63 & 66 \\
\hline \multicolumn{4}{|c|}{ Median PSA values at diagnosis } \\
\hline$\leq 10 \mathrm{ng} / \mathrm{mL}$ & 34 & 9 & 25 \\
\hline$>10 \mathrm{ng} / \mathrm{mL}$ & 8 & 5 & 3 \\
\hline \multicolumn{4}{|l|}{ Gleason grade } \\
\hline$<8$ & 26 & 6 & 20 \\
\hline$\geq 8$ & 16 & 8 & 8 \\
\hline \multicolumn{4}{|l|}{ Primary treatment } \\
\hline Radical prostatectomy & 13 & 5 & 8 \\
\hline Radiotherapy & 14 & 5 & 9 \\
\hline Both & 15 & 4 & 11 \\
\hline LH-RH therapy & 18 & 9 & 9 \\
\hline Mean PSA values at & 4.3 & 6.2 & 3.3 \\
\hline \multicolumn{4}{|l|}{ recurrence, ng/mL } \\
\hline \multicolumn{4}{|l|}{ Site of recurrence } \\
\hline Biochemical failure & 7 & I & 6 \\
\hline Prostate & 14 & 5 & 9 \\
\hline Nodal & 6 & 0 & 6 \\
\hline Bone + nodal & 3 & 1 & 2 \\
\hline Bone only & 12 & 7 & 5 \\
\hline
\end{tabular}

Notes: Group A: CTC-positive patients. Group B: CTC-negative patients. Abbreviations: $\mathrm{CTC}$, circulating tumor cell; $\mathrm{LH}-\mathrm{RH}$, luteinizing hormone-releasing hormone; PSA, prostate-specific antigen.

and $6(21.4 \%)$ had nodal recurrence. In univariate analysis of the logistic regression model, the presence of CTCs was statistically correlated with the development of bone metastases $(\mathrm{OR}=4.0 ; 95 \% \mathrm{CI}: 1.0-15.9 ; P=0.05)$ but not with biochemical recurrence $(\mathrm{OR}=0.28$; 95\% CI: $0.32-2.61$; $P=0.3$ ). Although lacking statistical significance, a correlation was found between presence of CTCs and development of local recurrence $(\mathrm{OR}=1.17 ; 95 \% \mathrm{CI}: 0.30-4.52 ; P=0.8)$. Finally, correlation between CTC positivity and nodal recurrence was not analyzed due to the absence of cases of nodal recurrence in Group A.

\section{Discussion}

Several studies showed the prognostic role of CTCs in patients with metastatic castration-resistant prostate cancer (mCRPC). ${ }^{6,7}$ Recently, data from $>263$ evaluable patients with mCRPC enrolled in a Phase 3 trial (SWOG S0421) showed that detection of CTCs at baseline (pretreatment) is a strong prognostic marker during chemotherapy with docetaxel. ${ }^{14}$ In

Table 2 Numerical variables according to group differences

\begin{tabular}{llll}
\hline Variables & Group A & Group B & P-value \\
\hline Median age, years (range) & $63(45-84)$ & $66(44-86)$ & 0.7 \\
$\begin{array}{l}\text { Median time to first } \\
\text { recurrence, months (95\% Cl) }\end{array}$ & $32(18-42)$ & $40(12-72)$ & 0.6 \\
$\begin{array}{l}\text { Mean PSA values at } \\
\text { recurrence, ng/mL (range) }\end{array}$ & $6.2(0.2-18.6)$ & $3.3(0.2-15.8)$ & 0.5 \\
\hline
\end{tabular}

Notes: Group A: CTC-positive patients. Group B: CTC-negative patients. Abbreviations: CTC, circulating tumor cell; PSA, prostate-specific antigen. 
Table 3 Categorical variables according to group differences

\begin{tabular}{lllll}
\hline Variable & Categories & $\begin{array}{l}\text { Group A, } \\
\text { n (\%) }\end{array}$ & $\begin{array}{l}\text { Group B, } \\
\text { n (\%) }\end{array}$ & \\
\hline Primary & Radical prostatectomy & $5(35.7)$ & $8(28.5)$ & 0.25 \\
treatment & Radiotherapy & $5(35.7)$ & $9(32.1)$ & \\
& Both & $4(28.5)$ & $11(39.2)$ & \\
Sites of & Bone & $8(57.1)$ & $7(25)$ & $\mathbf{0 . 0 4}$ \\
recurrence & Non-bone & $6(42.8)$ & $21(75)$ & \\
Gleason score & $<8$ & $6(42.8)$ & $20(71.4)$ & 0.07 \\
& $\geq 8$ & $8(57.1)$ & $8(28.5)$ & \\
\hline
\end{tabular}

Notes: Group A: CTC-positive patients. Group B: CTC-negative patients. Statistically significant value is shown in bold.

Abbreviation: CTC, circulating tumor cell.

addition, Scher et al evaluated the role of CTCs in mCRPC patients enrolled in the COU-AA-301 Phase 3 trial. ${ }^{13}$ The trial compared abiraterone plus prednisolone to placebo plus prednisolone in patients who progressed after docetaxel. Although CTCs alone failed to show a prognostic significance, the combination of CTCs and lactate dehydrogenase (LDH) levels at 12 weeks showed a prognostic role and met all surrogacy criteria for survival. In accordance with these findings, we confirmed a predictive role of CTCs in patients with recurrent prostate cancer. In fact, the subgroup of patients with a positive CTC count at baseline had a higher PSA mean value at recurrence and higher Gleason score in comparison to men with undetectable CTCs. Positive CTC status at baseline was also associated with shorter disease-free survival (DFS; Tables 2 and 3). It is well known that not all patients with recurrent prostate cancer have the same prognosis. Thus, it is important to identify not only patients at "high risk" of recurrence but also the type of recurrence most likely to occur, namely, local or distant. In this context, several factors have been investigated to evaluate the risk of recurrence, ${ }^{15,16}$ but none of these potential factors has demonstrated reliability as predictor of bone metastases. Our results suggest that CTCs may be helpful in identifying a subgroup of patients who are at high risk of developing bone metastases.

However, we report some important limitations to our approach: the small sample size precludes definitive conclusions; furthermore, our patients received different primary treatments (RT, surgery or both); and finally our study is a retrospective study, with its related intrinsic limitations and risk of bias.

\section{Conclusion}

Despite the small number of patients, the significant association between the presence of CTCs and tumor recurrence in the bone in patients with hormone-sensitive prostate cancer supports the hypothesis that CTCs may be considered a predictive marker of recurrence. However, further prospective studies with larger numbers of patients are required to confirm our results.

\section{Disclosure}

The authors report no conflicts of interests in this work.

\section{References}

1. Amling CL, Blute ML, Bergstralh EJ, Seay TM, Slezak J, Zincke H. Long-term hazard of progression after radical prostatectomy for clinically localized prostate cancer: continued risk of biochemical failure after 5 years. $J$ Urol. 2000;164(1):101-105.

2. Potosky AL, Davis WW, Hoffman RM, et al. Five-year outcomes after prostatectomy or radiotherapy for prostate cancer: the prostatecancer outcomes study. J Natl Cancer Inst. 2004;96:1358-1367.

3. Chism DB, Hanlon AL, Horwitz EM, Feigenberg SJ, Pollack A. A comparison of the single and double factor high risk models for risk assignment of prostate cancer treated with 3D conformal radiotherapy. Int J Radiat Oncol Biol Phys. 2004;59(2):380-385.

4. Lee AK, D'Amico AV. Utility of prostate-specific antigen kinetics in addition to clinical factors in the selection of patients for salvage local therapy. J Clin Oncol. 2005;23(32):8192-8197.

5. Mason MD, Sydes MR, Glaholm J, et al. Oral sodium clodronate for nonmetastatic prostate cancer - results of a randomized doubleblind placebo-controlled trial: Medical Research Council PR04 (ISRCTN61384873). J Natl Cancer Inst. 2007;99(10):765-776.

6. Zhang T, Armstrong AJ. Clinical utility of circulating tumor cells in advanced prostate cancer. Curr Oncol Rep. 2016;18(1):3.

7. de Bono JS, Scher HI, Montgomery RB, et al. Circulating tumor cells predict survival benefit from treatment in metastatic castration-resistant prostate cancer. Clin Cancer Res. 2008;14(19):6302-6309.

8. Strijbos MH, Gratama JW, Schmitz PI, et al. Circulating endothelial cells, circulating tumour cells, tissue factor, endothelin- 1 and overall survival in prostate cancer patients treated with docetaxel. Eur J Cancer. 2010;46(11):2027-2035.

9. Goodman OB Jr, Symanowski JT, Loudyi A, Fink LM, Ward DC, Vogelzang NJ. Circulating tumor cells as a predictive biomarker in patients with hormone-sensitive prostate cancer. Clin Genitourin Cancer. 2011;9(1):31-38.

10. Thompson I, Thrasher JB, Aus G, et al. Guideline for the management of clinically localized prostate cancer: 2007 update. J Urol. 2007; 177(6):2106-2131.

11. Roach M, Hanks G, Thames H Jr, et al. Defining biochemical failure following radiotherapy with or without hormonal therapy in men with clinically localized prostate cancer: recommendations of the RTOGASTRO Phoenix Consensus Conference. Int J Radiat Oncol Biol Phys. 2006;65(4):965-974.

12. Slovin SF, Wilton AS, Heller G, Scher HI. Time to detectable metastatic disease in patients with rising prostate specific antigen values following surgery or radiation therapy. Clin Cancer Res. 2005;11(24): 8669-8673.

13. Scher HI, Heller G, Molina A, et al. Circulating tumor cell biomarker panel as an individual-level surrogate for survival in metastatic castration-resistant prostate cancer. J Clin Oncol. 2015;33(12):1348-1355.

14. Goldkorn A, Ely B, Quinn DI, et al. Circulating tumor cell counts are prognostic of overall survival in SWOG S0421: a phase III trial of docetaxel with or without atrasentan for metastatic castrationresistant prostate cancer. J Clin Oncol. 2014;32(11):1136-1142.

15. Briganti A, Suardi N, Gallina A, et al. Predicting the risk of bone metastasis in prostate cancer. Cancer Treat Rev. 2014;40(1):3-11.

16. Francini E, Petrioli R, Rossi G, Laera L, Roviello G. PSA response rate as a surrogate marker for median overall survival in docetaxel-based first-line treatments for patients with metastatic castration-resistant prostate cancer: an analysis of 22 trials. Tumour Biol. 2014;35(11): $10601-10607$ 
OncoTargets and Therapy

\section{Publish your work in this journal}

OncoTargets and Therapy is an international, peer-reviewed, open access journal focusing on the pathological basis of all cancers, potential targets for therapy and treatment protocols employed to improve the management of cancer patients. The journal also focuses on the impact of management programs and new therapeutic agents and protocols on

patient perspectives such as quality of life, adherence and satisfaction. The manuscript management system is completely online and includes a very quick and fair peer-review system, which is all easy to use. Visit http://www.dovepress.com/testimonials.php to read real quotes from published authors.

Submit your manuscript here: http://www.dovepress.com/oncotargets-and-therapy-journal 